\title{
O Enfoque de Risco na Programação em Saúde: Fundamentos e Perspectivas
}

\section{José Ricardo de Carvalho Mesquita Ayres*}

O primeiro texto a tratar o "enfoque de risco" de forma sistemática, tornando-se referência clássica sobre o tema, foi publicado em 1978, pela $\mathrm{OMS}^{(9)}$. Retomado de forma mais amadurecida e generalizante alguns anos depois, 0 enfoque de risco consolida-se conceitualmente como um instrumento discriminador de diferentes probabilidades objetivas de danos determinados em individuos, familias e grupos sociais, fornecendo um critério tecno-científico para a organização à Saúde ${ }^{(5)}$. Porém, embora tal conceito remeta a pressupostos, métodos e procedimentos práticos bem particularizados, as principais discussões relacionadas às aplicações práticas do conceito de risco em saúde nunca estiveram muito atreladas à específica construção do "enfoque" de risco, ou RA (risk approach).

Independentemente da sistemática proposta pelo RA, a utilização do conceito de risco como um orientador da intervenção, especialmente aquela de corte sanitário, penetrou profundamente o conjunto das práticas de saúde. Tal penetração deu-se com uma amplitude e com uma "falta de rigor" metodológico de que, possivelmente, jamais suspeitariam os ideólogos do RA. Embora, aqui e ali, métodos de aferição e escores de risco possam ainda ser encontrados, o conceito de risco, por força de sua própria dinâmica histórica, tornou-se menos uma metodologia para a ação que um conjunto de preocupações e concepções tecno-normativas tão assistemáticas quanto inextrincavelmente ligadas às concepções de saúde contemporâneas. Ganhando, de um lado, o coração da investigação científica, e, de outro lado, expressivas representações no senso comum, o risco é hoje um "procurador" de todo dano ou ameaça de dano em saúde.

* Professor Doutor do Departamento de Medicina Preventiva da Faculdade de Medicina da USP. 
Uma apreciação de ordem semelhante precisa ser feita em relação à programação. Também aqui a terminologia refere-se, classicamente, a uma determinada proposição de organização do trabalho sanitário que está longe de ter alcançado uma organicidade e efetividade histórica que nos permita falar em "programação" sem o ônus de uma acentuada polissemia. Na perspectiva aqui adotada, a programação é compreendida como uma tecnologia de organização do trabalho assistencial, que busca realizar, no âmbito da atenção primária, a chamada integração médico-sanitária, isto é, um tratamento articulado $e$ mutuamente enriquecedor das necessidades assistenciais objetivadas no plano individual e aquelas objetivadas no plano coletivo em que as primeiras estão consubstanciadas $^{(8)}$.

Nesse sentido, podemos destacar dois pressupostos dialéticos, ou "apostas" práxicas, que embasam a concepção de ação programática e que justificam a relevância da aplicação do conceito de risco. São eles: a) a demanda espontânea pela assistência à saúde, tal como realizada nos serviços, não recobre as necessidades de saúde experimentadas cotidianamente pelos indivíduos; b) ampliação dos serviços de saúde oferecidos não significa aumento da efetividade de ações.

Estas formulações querem apontar a positividade histórica de uma esfera de necessidades cujo reconhecimento e validação intersubjetiva não se dão, senão de forma muito mediada e (na mesma proporção) ideologicamente comprometida, no âmbito das práticas médico-assistenciais de corte estritamente clíni$\mathrm{co}^{(7)}$. Para que tais necessidades, socialmente delimitadas, sejam transformadas em objetos do trabalho em saúde, é preciso que se constituam, na relação concretamente estabelecida entre profissionais e população-alvo, os sujeitos capazes de dar voz às mesmas, tanto no "lado" dos profissionais quanto no da população-alvo. Para que isso aconteça é preciso superar a restrição à universalização que a tradução estritamente clínica realiza na assistência à saúde (durante e além do momento propriamente assistencial). Para que isso aconteça, é preciso recorrer a elementos tecnológicos que realizem uma operação de certa forma inversa ao do trabalho clínico tradicional: ao invés de se buscar trazer toda a diversidade de determinações do dano em questão para uma totalização que conflua para um padrão normativo (e para um objeto de aplicação dessa normatividade) regular e constante, é preciso encontrar elementos que "discriminem" normas e objetos, diferenciando sujeitos particulares relacionados a processos específicos de interesse ${ }^{(3)}$.

Aqui programação e epidemiologia confluem: para as duas, uma como trabalho e outra como ciência, a necessidade de um elemento estratégico, capaz de realizar essa discriminação "especificadora e instrumental" tornou-se imperativa - para a ciência epidemiológica por exigência de seus processos de validação epistemológica ${ }^{(4)}$, para a programação como condição de efetividade téc- 
nica; em ambos os casos como condição concreta de construção da ordem social a que estão articuladas.

A questão que se impõe pensar, contudo, é até que ponto o conceito de risco, enquanto elemento estratégico, é capaz de discriminar e efetivar a presença real de sujeitos em processos concretos de trabalho em saúde. Para além de todos os limites epistemológicos e práticos da aplicação do risco à organização do trabalho em saúde, já discutidos por outros autores ${ }^{(1,6)}$, um aspecto ainda relativamente pouco explorado, apesar de fundamental na relação entre risco e programação, é a "velha" questão de que no trabalho em saúde os objetos são sujeitos. A utilização do risco, com toda sua eficácia estratégica, não pode ser abstraída do fato de que, embora, caminhe num sentido "analítico-discriminativo", ao invés de sintéticouniversalizante, o risco não rompe com o caráter objetivista que marca os saberes tecno-científicos. Se o raciocínio da clínica "dessubjetiva" as necessidades de saúde com que trabalha por sua lógica universalizante, o raciocínio epidemiológico-programático padece do mesmo mal quando trata os constructos fragmentários e abstratos efetuados pelo risco como expressão imediata das "reais necessidades" de saúde ${ }^{(2)}$. Com efeito, embora o núcleo tecnológico do trabalho em saúde seja o fundamento da relação entre esses dois sujeitos genéricos - serviço de saúde e população - as práticas assistenciais não podem ser pensadas como ações estritamente técnicas sem reduzir o pólo população a uma realidade "plana e estanque", que ela não é. Se recorremos ao risco para evitar a "morte" do sanitário como esfera objetiva de necessidades, se queremos resgatar pelo social a autêntica subjetividade de nossos "objetos" de prática, então a relação entre risco e programação precisa ser revista. Precisaremos incorporar a nossas práticas cotidianas a idéia de risco como construção abstrata de caráter sempre (imediatamente) prescritivo, e o caráter quase-tecnológico da programação. Talvez assim, sem a descaracterização ideológica de qualquer um dos lados, possamos conseguir efetiva expressão dos sujeitos envolvidos no grande diálogo das práticas de saúde, no qual a técnica não é senão uma entre as diversas linguagens utilizadas.

\section{Referências Bibliográficas}

1. ALVARENGA, A. T. O conceito de risco na área materno-infantil: considerações teóricas, metodológicas e de aplicação. São Paulo, 1984 [Tese de Doutorado - Faculdade de Saúde Pública da USP].

2. AYRES, J. R. C. M. Ação programática e renovação das práticas médicosanitárias: saúde e emancipação na adolescência. Saúde em Debate, 42:54-8, 1994.

3. AYRES, J. R. C. M. Adolescência e saúde coletiva: aspectos epistemológicos da abordagem programática. In: Schraiber, L. B. Programação em saúde hoje. 2a. ed., São Paulo, Hucitec, 1993, p. 139-82. 
4. AYRES, J. R. C.M. Epidemiologia e emancipação. São Paulo, Hucitec Abrasco, 1995.

5. BACKETT, E. M.; DAVIES, A. M.; PETROS-BARZAVIAN, A. The risk approach in health care., Geneva, World Health Organization, 1984. (Public Health Papers, No 76)

6. HAYES, M. v. The risk approach: unassailable logic? Soc. Sci. Med. 33:5570, 1991.

7. MENDES-GONÇALVES, R. B. Reflexões sobre a articulação entre a investigação epidemiológica e a prática médica a propósito das doenças crônicas e degenerativas. In: Costa, D. C. org. Epidemiologia - teoria e objeto. São Paulo, Hucitec, 1993 p. 39-86.

8. SCHRAIBER, L. B. org. Programação em saúde hoje. São Paulo, Hucitec, 2a ed. 1993

9. WORLD HEALTH ORGANIZATION. Risk approach for maternal and chld health care. Geneva, 1978. WHO Offset Publication, No 39 